\title{
Metrobüs Şaft Torkunun Sınırlandırılmasına Yönelik Hibrit Güç Aktarma Yapısı ve Güç Yönetim Sistemi Tasarımı
}

\author{
Design of Hybrid Power Transmission Architecture and Power Management Strategy for \\ Metrobus Shaft Torque Limitation
}

\author{
Volkan SEZER* \\ İstanbul Teknik Üniversitesi, Elektrik-Elektronik Fakültesi, Kontrol ve Otomasyon Müh. Bölümü, İstanbul, Türkiye
}

• Geliş tarihi / Received: 26.05.2017 • Düzeltilerek geliş tarihi / Received in revised form: 06.11.2017 • Kabul tarihi / Accepted: 13.11 .2017

\begin{abstract}
$\ddot{O} z$
Bu yayında, İstanbul trafiğinde aktif olarak kullanılmakta olan metrobüslerin kullanım ömürlerinin artırılmasına yönelik bir hibrit güç aktarma mimarisi önerilmiş, bu yapıyla birlikte kullanılacak bir güç yönetim algoritması geliștirilmiş ve yeni ortaya çıkan sonuçlar analiz edilmiştir. Çalışmanın amacı mevcut metrobüslerin çekiş barındırmayan aksına iki adet harici elektrik motoru takılarak, bu motorların uygun durumlarda devreye alınmasıyla aracın orijinal çekiş yükünün azaltılması ve şaft torkunun sınırlandırılmasıdır. Bu sayede, şaft ömrünün artırılması amaçlanmıştır. Eklenecek motorların ne zaman devreye alınıp devreden çıkarılacağına, ne zaman motor veya jeneratör olarak çalıştırılacaklarına yönelik kararları alacak güç yönetim algoritması, öncelikle benzetim ortamında denenmelidir. Benzetimlerin gerçekçi sonuç verebilmesi için ise, aracın ve yolun yüksek doğrulukla modellenmesi gerekmektedir. Benzetimlerde kullanılan tek izli boylamsal dinamik modelin geliştirilebilmesi için, metrobüs üzerinden sürüş esnasında deneysel veri toplanmış ve bu veriler model içerisine entegre edilmiştir. Bunun yanında metrobüs hattına ait eğim ve hızlanma verileri de elde edilerek performans benzetimleri için altyapı oluşturulmuştur. Ayrıca güç yönetim algoritmasının geliştirilebilmesi için, aracın orijinal durumunda şoförün hangi gaz pedal açıklığında ne kadar tork talebinde bulunduğuna dair haritanın da bilinmesi oldukça kritiktir ve bu çalışmada bu haritanın nasıl elde edildiği de gösterilmektedir. Son olarak, güç yönetimi için geliştirdiğimiz kural tabanlı bir kontrol algoritması hakkında bilgi verilmiş ve elde edilen sonuçlar analiz edilmiştir. Yapılan benzetimler sonucunda, kullanılan tork-hasar eğrisine göre şaft ömrünün \%75.86 oranda artırıldığı gözlemlenmiştir.
\end{abstract}

Anahtar kelimeler: Güç Yönetimi, Hibrit Araçlar, Taşıt Modelleme, Taşıt Simülasyonu

\begin{abstract}
In this paper, an improved hybrid powertrain is proposed for extending the lifetime of original drive shaft of the Metrobuses that are being actively used in Istanbul traffic. A new power management method for the proposed powertrain is developed and the results of the method are analyzed along the study. The aim of the study is decreasing the operating load of the original axle and extend its lifetime by mounting two additional electric machines to one of the non-driven axles. The power control method which calculates the correct timing of the machines when to be used as a motor/generator or when to activate and deactivate them, should be tested in simulation environment first. In order to get realistic results from simulations, the models must be reliable. In order to develop the single-track dynamic model of the vehicle, experimental data is collected under real driving condition and is integrated into the model. Besides this, the collected road slope and metrobus acceleration data provides an infrastructure for performance simulations. On the other hand, the throttle-torque map is very critical to understand the driver's torque request. In this study, derivation of the torque map from experimental data is also explained. Finally, a rule based power management algorithm for lifetime extension is developed along the paper and its results are analyzed at the end of the work. According to the simulation results, the lifetime of the driving shaft of the original metrobus is extended by $75.86 \%$ in proposed hybrid powertrain.
\end{abstract}

Keywords: Power Management, Hybrid Vehicles, Vehicle Modeling, Vehicle Simulation

* Volkan SEZER; sezerv@itu.edu.tr, Tel: (0212) 2857005 (dahili: 116); orcid.org/0000-0001-9658-2153 


\section{Giriş}

Hibrit araç teknolojisi, son yıllarda önemi oldukça artan ve üzerinde yoğun araştırmalar yürütülen popüler bir konudur. Yapısı gereği 1'den fazla enerji kaynağ 1 kullanmakta olan bu araçların temel kullanım amacı, yakıt tüketiminin ve doğaya salınan zararlı emisyonların azaltılmasıdır (Sezer ve Gökaşan, 2011). Hibrit araçlarda emisyon ve yakıt tüketimini azaltmaya yönelik metodlar karşılaştırmalı olarak Pisu ve Rizzoni (2007) tarafından yapılan çalışmada incelenebilir. $\mathrm{Bu}$ çalışmada ele alınan Phileas marka metrobüs araçları (Siuru, 2004) İstanbul şartlarında kullanıldığında ortaya çıkan yüksek miktarlardaki tork ihtiyac1 nedeniyle mekanik problemlerle karşılaşmakta ve sık sık bakım altına alınmaktadır. Bu gerçek problemden yola çıkarak, aracın çekiş olmayan başka bir aksına 2 adet elektrik motoru takılarak, aracın orijinal tork yükünün azaltılması düşünülmüştür. (Sezer vd., 2015) çalışmasında, metrobüslerin çekiş karakteristiğini artırmaya yönelik bir yaklaşım verilmiş fakat buradaki yöntem şaft ömrünün artımına yönelik tasarlanmamış, dolayısıyla sonuçların şaft ömrünün artımına etkileri göz ardı edilmiştir. $\mathrm{Bu}$ sebeplerden, ilgili çalışmada yorulma ve şaft ömrü ile ilgili herhangi bir analiz gerçekleştirilmemiştir.

Buradaki çalışmada sisteme eklenen elektrik motorlarının amacı çekiş artırma veya yakıt ekonomisinden ziyade şaft ömrünü uzatmak olacaktır. $\mathrm{Bu}$ bağlamda seçilen elektrik motorlarının ne zaman ve hangi tork miktarlarında devreye girip ne zaman jeneratör olarak elektrik enerjisi üreteceğine karar verecek üst seviye bir kontrol algoritmasına ihtiyaç duyulacaktır. $\mathrm{Bu}$ kontrol algoritmasının tasarımı ve ilk testleri, gerçekçi araç modelleri kullanılarak benzetim ortamında gerçekleşmelidir.

Bir diğer önemli nokta ise aracın orijinal sisteminin gaz pedal açıklığı ve motor dönüş hızına göre nasıl bir tork ürettiğinin bilinmesi gerekliliğidir. $\mathrm{Bu}$ çalışmada öncelikle araç/hat modellemesi ve pedal açıklığına göre araç orijinal tork karakteristiğinin belirlenmesi için yapılan veri toplama çalışmalarından bahsedilmiştir. Daha sonra, harici komponentler ve hiz kontrolörüyle birlikte elde edilen bütünleşik araç modeli anlatılmıştır.

Son olarak problemin çözümüne yönelik önerilen hibrit mimari ve yeni hibrit mimarinin güç yönetimine yönelik geliştirilen kural tabanlı yeni bir algoritmadan bahsedilmekte ve sonuçları analiz edilmektedir.

\section{Veri Toplama ve Araç Modelleme Çalışmaları}

Araç modelleme, tasarım sürecini oldukça hızlandıran ve geliştirilen algoritmaların hızlı ve güvenli olarak denenmesini mümkün k1lan önemli bir aşamadır. Bazı araç modelleri yalnızca benzetim amacıyla gerçekleştirilirken, bazıları da doğrudan geliştirilen model tabanlı kontrolörler içerisinde çalışması amacıyla tasarlanabilir (Brosilow ve Joseph, 2002). Araçların matematiksel modellemesi, basitten karmaşığa doğru çok farklı şekillerde yapılabilir (Rajamani, 2006). Bu çalışmada aracın güç yönetimine yönelik iyileştirme gerçekleştirileceğinden, aracin yanal dinamiğinden daha çok boylamsal dinamiği önem kazanmaktadır. Bu nedenle bu çalışmada tek izli boylamsal araç modeli oluşturulmasına karar verilmiştir.

\subsection{Tek İzli Boylamsal Araç Modeli}

Boylamsal araç modelinde en temel yapı tekerleklerdir. $\mathrm{Bu}$ çalışmada tekerlek, Pacejka tekerlek modeli yaklaşımıyla modellenmiştir. Lineer olmayan Pacejka tekerlek modeline ait parametreler deneysel olarak elde edilebilmektedir (Denta, 1997). Tekerlek modelinin görevi, kayma (s) girişine karşılık hareketi sağlayan tekerlek yol arası kuvvetin (Fx) hesaplanmasıdır. Tekerlek kayması, tekerlek doğrusal hızıyla araç doğrusal hızı arasındaki orandır. $\mathrm{Bu}$ oran, frenleme ve ivmelenme için farklı tanımlanmıştır. Tekerlek kaymasını frenleme ve ivmelenme için tanımlayan eşitlikler Denklem (1)'de gösterildiği gibidir.

$s=\frac{w R-V}{w R} \rightarrow$ İvmelenme
$s=\frac{w R-V}{V} \rightarrow$ Frenleme

(w: Tekerlek açısal hızı, V: Araç çizgisel hızı, R: Tekerlek yarıçapı)

Kayma hesabı sonrasında araca etkiyen itiş kuvveti tekerlek modeli yardımıyla elde edilir. $\mathrm{Bu}$ itiş kuvvetinin karşısında ise; yuvarlanma direnç kuvveti, aerodinamik direnç kuvveti, yol eğiminden gelen kuvvet ve ivmelenmeden dolay1 gelen kuvvet yer almaktadır. Boylamsal dinamik içerisinde bu ilişki, Şekil 1'de gösterilmiştir. 
Şekil 1'de gösterilen ilişkiyi ifade eden matematiksel bağıntı, Denklem (2)'de gösterilmiştir.

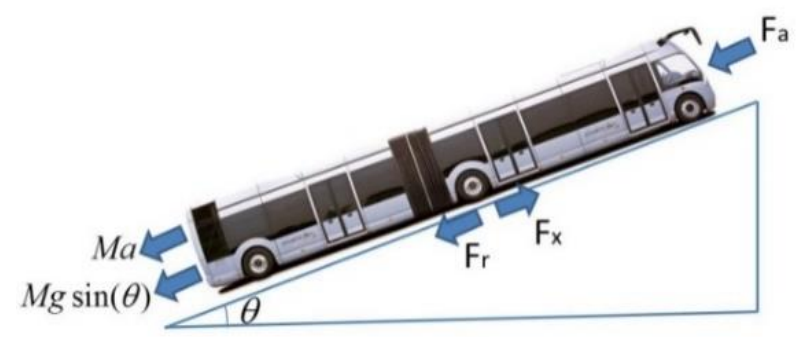

Şekil 1. Araca etkiyen boylamsal kuvvetler

$F_{x}=M a+F_{a}+F_{r}+M g \sin (\theta)$

(M: Araç kütlesi, g: yerçekimi ivmesi, a: Araç boylamsal ivmelenmesi, Fr: Yuvarlanma direnci kuvveti, Fa: Aerodinamik direnç kuvveti, $\theta$ : Yol eğimi)

Denklem (2)'de yer alan aerodinamik direnç ve yuvarlanma direnci kuvveti ifadeleri ise Denklem (3) ve Denklem (4)'te gösterilen standart formüllerle hesaplanabilmektedir.

$F_{a}=\frac{1}{2} \rho A V^{2}$

$F_{r}=M g f$

( $\rho$ : Aerodinamik direnç katsayısı, A: Araç ön projeksiyon alanı, V: Araç boylamsal hızı, f: Yuvarlanma direnç katsayısı).

\subsection{Metrobüs Hattindan Veri Toplama Çalışmaları}

Denklem (2)'de görüldüğü üzere, sürüş esnasında 4 farklı direnç kuvveti araca etki etmektedir. Bu kuvvetlerin metrobüs için ne büyüklükte olduklarını bulabilmek adına pist üzerinde gerçek bir metrobüse ait sürüş verilerini toplamak gerekmektedir. Etkiyen direnç kuvvetleri, araç ivme bilgisi, hiz bilgisi ve yol eğiminin fonksiyonlarıdır. $\mathrm{Bu}$ nedenle sürüşe ait ivme, hız ve eğim açısı bilgilerini toplayabilmek için, gerçek bir metrobüs üzerine Trimble AG332 marka hassas bir GPS alıcısı ile 3 eksende açısal ivme, hız ve açı bilgisini veren Crosbow VG 700AB-201 marka IMU monte edilmiştir. Bu enstrümantasyona ilişkin görseller, Şekil 2'de verilmiştir.
Şekil 2'de gösterilen sistemde, GPS anteni araç üzerine ve ağırlık merkezi hizasında bir bölgeye yerleştirilmiştir. Benzer şekilde IMU ölçümlerinin de doğruya en yakın elde edilebilmesi için sensör, aracın ağırlı merkezine sabitlenerek monte edilmiştir. GPS ve IMU verilerini senkronize olarak toplayıp kaydetmek için, National Instruments ${ }^{\circledR} \quad$ firmasının sağladığı Labview ortamı kullanılarak bir veri toplama yazılımı geliștirilmiștir. Bu yazılımın görevi, IMU'nün ilk kalibrasyonunu gerçekleştirmek, IMU üzerinden $10 \mathrm{~Hz}$, GPS üzerinden ise $1 \mathrm{~Hz}$ 'de veri toplamak ve her veriye zaman bilgisini de ekleyerek uygun formatta kayit almaktır.

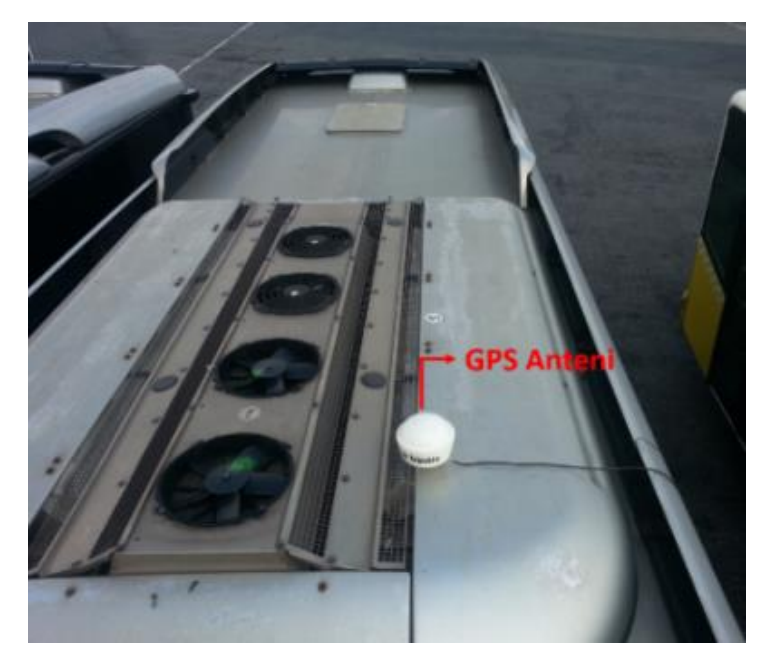

a: GPS Anteninin Metrobüs Üzerine Montaj1

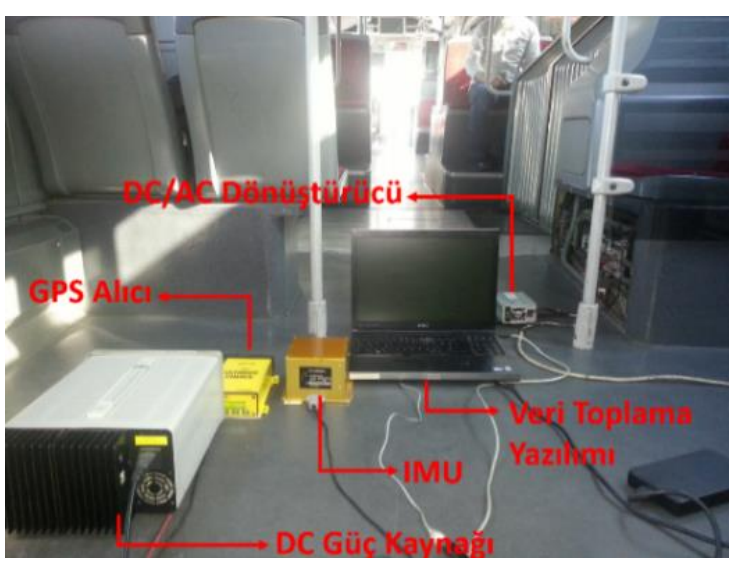

b: Metrobüs İçerisine Yerleştirilen 3 eksenli IMU, GPS alıcısı, Veri Toplama Bilgisayarı DC/AC Dönüştürücü ve Güç Kaynağı

Şekil 2. Veri Toplama Enstrümentasyonu

Sensörler yardımıyla toplanan veriler Tablo 1'de gösterilmiştir.

Şekil 3'te, toplanan veriler arasından örnek olarak seçilen 10 dakikalık yol eğimi ve araç hızı bilgisi gösterilmektedir. Bu elde edilen verilerle, hatta ait 
benzetimlerin yapılabileceği gerekli ivmelenme, hız profili ve yol eğimi verileri elde edilmiştir.

$\mathrm{Bu}$ veriler, çalışmanın ilerleyen kısımlarında açıklanacak harici elektrik motorları ve batarya sistemi ile hibritizasyonu sağlanacak metrobüsler için gerekli benzetimlerin yapılabilmesinde önemli rol oynamaktadır.

\subsection{Araç Tork Haritasının Elde Edilmesi}

Araçlarda yer alan tahrik motorları, kullanıcının pedal açıklığına ve o anki hızına göre belirlenen bir tork üretmektedir.

Tablo 1. Metrobüs hattı üzerinde toplanan veriler

\begin{tabular}{lc}
\hline $\begin{array}{c}\text { Crosbow VG 700AB-201 } \\
\text { (IMU) 10Hz }\end{array}$ & $\begin{array}{c}\text { Trimble AG332 } \\
\text { (GPS) } 1 \mathrm{~Hz}\end{array}$ \\
\hline Yunuslama Açı1 & Enlem \\
Yuvarlanma Açısı & Boylam \\
Yunuslama İvmesi & Yükseklik \\
Yuvarlanma İvmesi & Hiz \\
X yönünde doğrusal & Aktif Uydu \\
ivmelenme & Sayısı \\
Y yönünde doğrusal & \\
ivmelenme & \\
Z yönünde doğrusal & \\
ivmelenme & \\
Sicaklık & \\
\hline
\end{tabular}
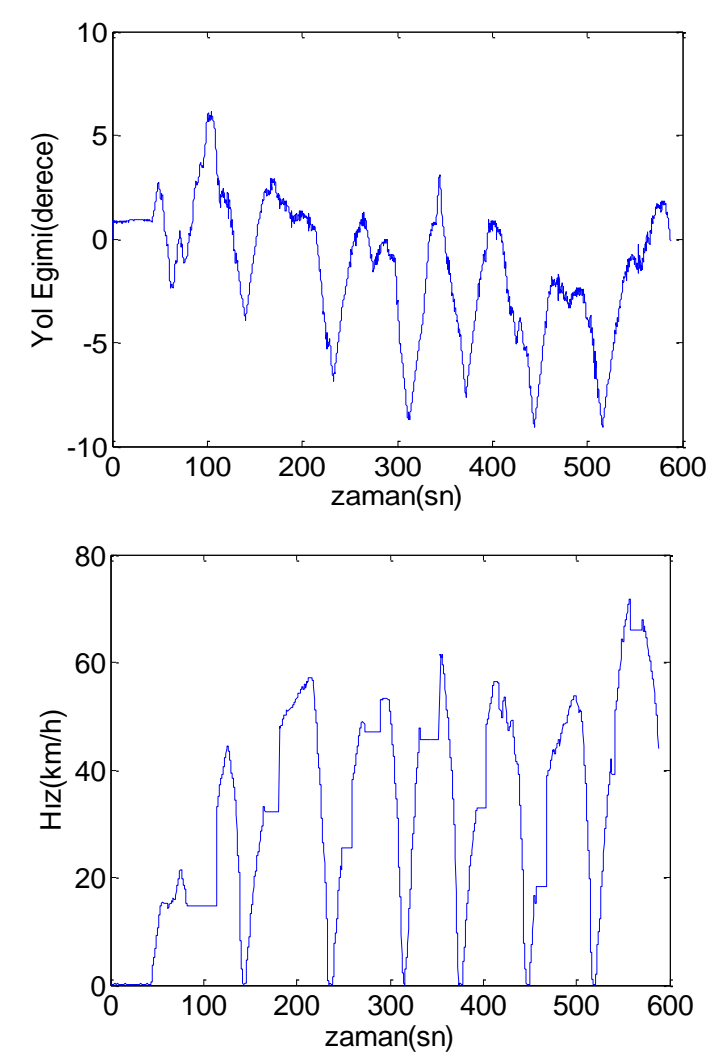

Şekil 3. Toplanan örnek veriler (yol eğimi, hız)
$\mathrm{Bu}$ istenen tork, motorun (dolayısıyla aracin) o anki hızına ve pedal açıklığına bağlı olarak motor kontrol ünitelerinin içerisindeki haritalarda saklanır. Araç üreticisi firmanın özel bilgileri arasında yer alması nedeniyle bu haritalara doğrudan ulaşma şansımız olmadığ bahsedilen haritanın çeşitli testler yardımıyla tersine mühendislik ile elde edilmesi yoluna gidilmiştir. $\mathrm{Bu}$ amaç doğrultusunda, aracın CAN (Controller Area Network) haberleșme hatt1 üzerinden pedal açıklığı, araç hızı ve hızlanma verileri eş zamanlı toplanarak, "Tek İzli Boylamsal Araç Modeli" kısmında gösterilen dinamik denklemler yardımıyla ne kadarlık tork üretildiği bilgisi hesaplanabilmiştir. Şekil 4'te, veri toplama ara yüzüne ait bir görüntü yer almaktadır.

CAN hatt1 üzerinden, $\% 22, \% 45, \% 73$ ve $\% 100$ olmak üzere, sabit miktarda basılan 4 pedal açıklığına ait hızlanma verileri ayrı ayrı toplanmıştır. $\mathrm{Bu}$ testler hattın düz kabul edilebilecek bölgelerinde yapıldığından, eğimden dolayı gelen kuvvetler ihmal edilmiştir.

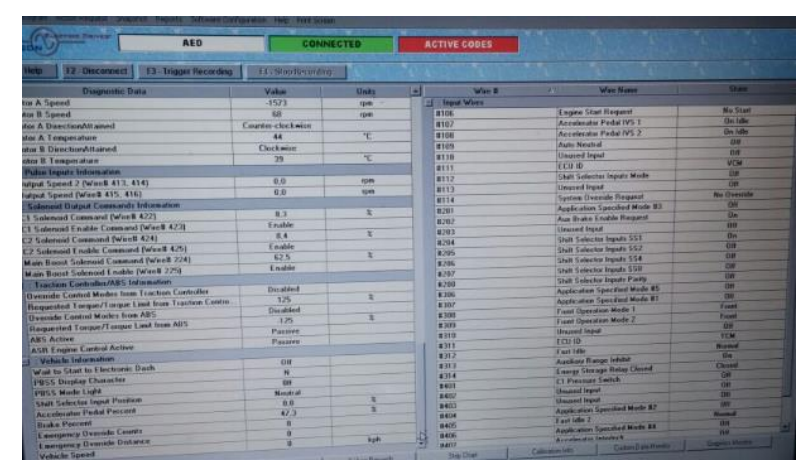

Şekil 4. CAN hattından veri toplama yazılımı arayüzü

Araca etkiyen ivmelenme, yuvarlanma direnci ve aerodinamik direnç kuvvetleri, araç parametrelerine göre hesaplanmış ve bu kuvveti sağlamak için motorların üretmesi gereken tork değerleri her bir pedal açıklığı için ayrı ayrı hesaplanmıştır. $\mathrm{Bu}$ tork değerleri hesaplanırken, aktarma organlarındaki çevrim oranları ve aktarma oranlarına ait yaklaşık mekanik verim değerleri de göz önünde bulundurulmuştur. Burada kullanılan model, probleme tersten yaklaştığımız için tersine araç modeli olarak adlandırılmıştır. 4 pedal açıklığı arasında kalan bölgeler içerisinde yapılan interpolasyon işlemi sonucunda, orijinal araca ait pedal açıklığı-hıztork haritası Şekil 5'te gösterildiği gibi elde edilmiştir. Burada kullanılan hız değeri, tekerlerin dönüş hızı olarak alınmıştır. 


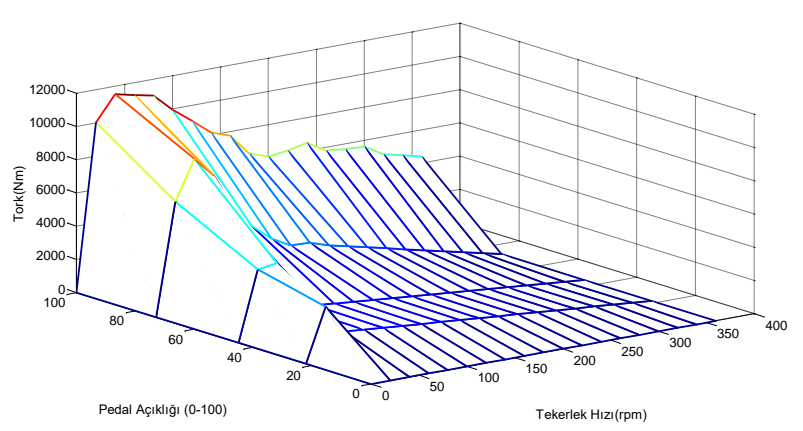

Şekil 5. Elde edilen pedal açıklığı-tekerlek hızıtork haritas1

\subsection{Harici Sistemler}

Çalışmanın 4. bölümünde önerilen hibrit mimaride kullanılan elektrik motoru ve batarya sistemine ait modeller, verim haritaları üzerinden geliştirilmiştir. Kullanılan batarya sistemi, daha önce tarafımızca yapılan çalışmada (Sezer, Gökaşan, 2011) kullanılan KOKAM marka SLBP-60460330 model lityum polimer hücrelerden oluşan 70Ah'lik bir sistemdir. 98 hücrenin seri bağlanmasıyla oluşturulan batarya sisteminin toplam enerjisi $25 \mathrm{kWh}$ olarak belirlenmiştir. Bataryaya ait verim haritası Şekil 6 'da gösterilmiştir.

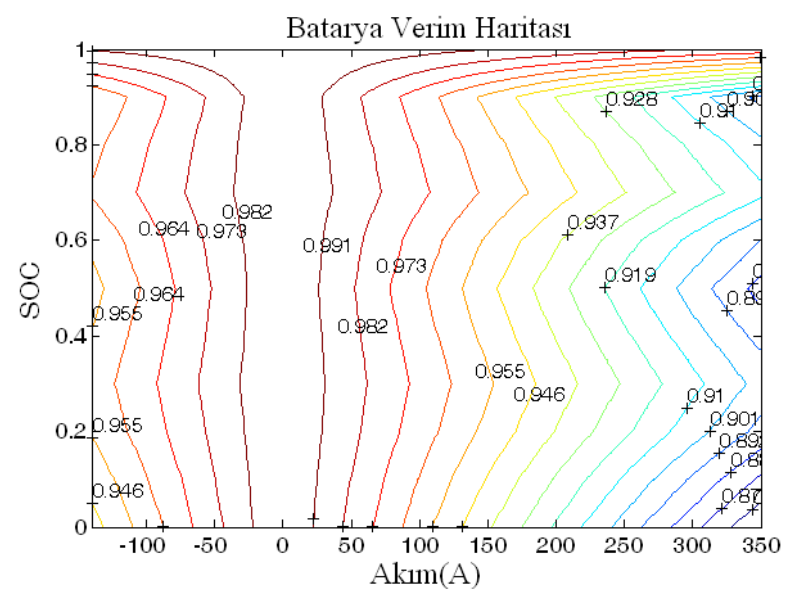

Şekil 6. Batarya verim haritası KOKAM-SLBP60460330

Elektrik motoru da yine benzer şekilde modele dahil edilmiştir. Çalışmada, piyasadan hali hazırda temin edilebilen REMY marka HVH250-090-S model numaralı elektrik motoru kullanılmıştır. Tork ve hıza bağlı olarak değişen verim haritası, doğrudan ilgili modelin kataloglarından elde edilmiş ve model içerisinde kullanılmıştır. Şekil 7'de, hem motor hem de jeneratör olarak çalışma durumlarına ait, kullanılan verim haritası gösterilmiştir.

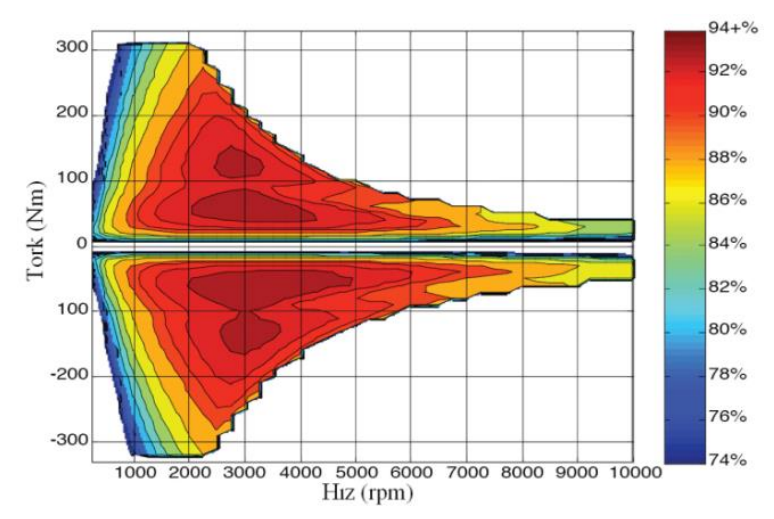

Şekil 7. Elektrik Motoru Verim Haritası (REMY HVH250-090-S)

\subsection{Bütünleşik Model}

Toplanan verilerin ve yapılan analizlerin ardından, orijinal araca eklenecek motorların ve bu motorların beslendiği harici batarya sisteminin de dahil olduğu bütünleşik bir boylamsal dinamik araç modeli geliştirilmesi üzerinde çalışılmıştır. Harici elektrik motorlarının modellenmesinde, motorların maksimum tork-hız karakteristikleri ve her bir çalışma noktasına ait verim değerlerini içeren verim haritaları kullanılmıştır. Araca eklenecek yeni batarya sistemine ait basit bir batarya modeli de bütünleşik modele dahil edilmiştir. $25 \mathrm{kWh}$ olarak seçilen batarya enerji kapasitesi Şekil 7'de gösterilen verim haritasıyla birlikte kullanılmıştır. Matlab/Simulink ortamında hazırlanan, tüm alt sistemlerin ve araç dinamiğinin bir arada bulunduğu bu modele ait görüntü, Şekil 8'de gösterilmektedir.

Araç modeline girilen sabit bir hız profilinin araç tarafindan izlenebilmesi için, sürücünün vermesi gereken gaz-fren açıklıklarını hesaplayan bir sürücü modeline (hız kontrolörü) ihtiyaç vardır. $\mathrm{Bu}$ yapı, Şekil 8'de "hız kontrolörü" bloğu içerisinde yer almaktadır. Sürekli durum hatalarını engelleyen ve istediğimiz takip karakteristiğini sağlayan bir oransal-integral PI kontrolörüyle verimli sonuç alınmıştır. PI kontrolörün oransal (Kp) ve integral (Ki) katsayıları, farklı profillerdeki performanslar arasında en yakın takip edecek şekilde deneme yanılma ile belirlenmiştir $\quad(\mathrm{Kp}=20, \quad \mathrm{Ki}=0.5)$. İlerleyen zamanlarda bu katsayıların analitik elde edilmesi üzerinde de çalışmalar planlanmaktadır. İntegral sarmas1 engelleyici (anti-windup) bir yapı da kontrolöre dahil edilmiştir (Bohn ve Atherton, 1995). Geliştirilen hız kontrolörünün performansı Şekil 9'da gösterilmektedir. 


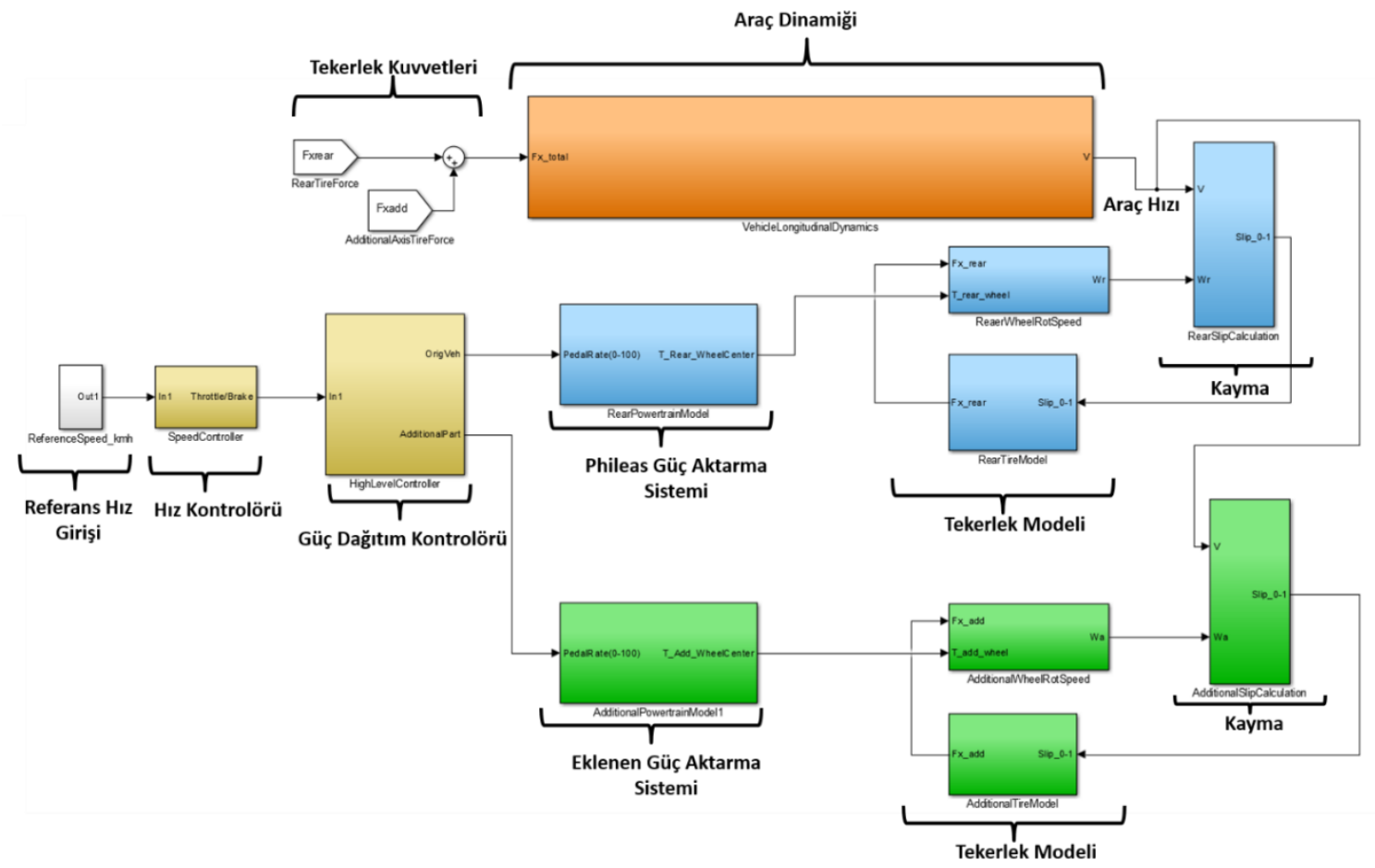

Şekil 8. Bütünleşik model simulink gösterimi

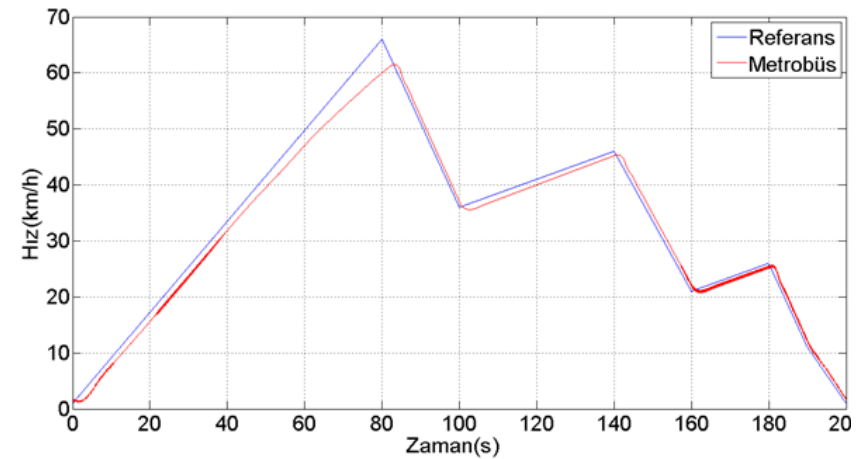

Şekil 9. H1z kontrolörü performans1

Şekil 9'da gösterilen hız profilini elde etmek için aracin orijinal durumunda (harici elektrik motorlarını dahil edilmeden) tahrik şaftının ürettiği tork değerleri Şekil 10'da görülmektedir.

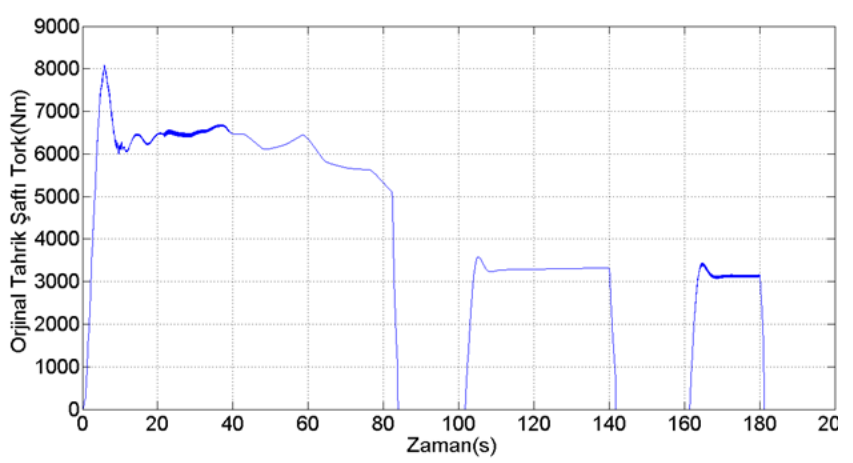

Şekil 10. Orijinal tahrik şaftı tork miktarı (Şekil 9'daki hız profili esnasında)

\section{Yorulma Analizi}

Şaft, genellikle dairesel yapıda olan, güç veya hareket iletmek için kullanılan dönel yapılardır (Shigley vd., 1989). Yorulma analizlerinde, sürüş esnasında şaft üzerine eğilmeden ve burulmadan dolayı etki eden gerilmelerin aynı anda oluşmasından dolayı eşdeğer gerilme yaklaşımından faydalanılmaktadır. Eşdeğer gerilmeyi etkileyen faktörler; eğilme, burulma ve aks yüklerinin etkisiyle oluşan gerilmelerdir. Dönen şaft üzerindeki kritik noktalarda, aks yükü nedeniyle oluşan gerilmelerin eşdeğer gerilmeye etkisi, eğilme ve burulma nedeniyle oluşanların yanında oldukça küçük olup, ihmal edilebilecek düzeydedir (Pradhan ve Gaikwad, 2015). Eğilme gerilmesi, yükün şaft üzerine etkiyen dikey bileşenlerinden dolayı oluşan gerilme olup, burulma gerilimi ise şaftın aktardığı tork miktarı ile doğrudan ilişkilidir. Bu çalışmadaki amaç şaft ömrünü uzatmak olduğu için, aracın ağırlığından dolayı oluşan dikey kuvveti değiştirmek yerine, doğrudan şafta aktarılan torku değiştirerek burulma gerilmesine müdahale edilmesiyle bu amaç gerçekleştirilmeye çalışılacaktır.

Literatürde yorulma analizi çalışmalarında, sabit gerilmeler altında malzemenin kaç çevrim sonunda çatlayacağını veya kırılacağını gösteren gerilme-çevrim eğrileri (S-N eğrileri) çokça kullanılmaktadır (Shigley vd., 1989). Öte yandan yukarıda da bahsedildiği gibi bu çalışmada, 
aktarılan torka yapılacak müdahale üzerinden şaft ömrü artırılmaya çalışılacağından, S-N eğrisi yerine tork-çevrim (T-N) eğrisi kullanılacaktır. T$\mathrm{N}$ eğrilerinin deneysel olarak edilmesi de mümkündür (Lee ve Barkey, 2005).

Şekil 11a ve $11 \mathrm{~b}$, torkun yorulma üzerine etkisini farklı bakış açılarıyla göstermektedir. N, malzemenin kırılması için geçmesi gereken çevrim (tur) sayısıdır. Şekil 11a, her bir tork değeri için kaç tur dönüş gerçekleşirse malzemenin kırılacağını göstermektedir ve Lee ve Barkey'in (2005) çalışmasında yer alan çalışma sonucunda deneysel olarak elde edilmiştir. Örneğin $200 \mathrm{Nm}$ tork iletilmesi durumunda 500000 devir sonunda malzemenin kırılacağ1 grafikten elde edilebilmektedir. Şekil $11 \mathrm{~b}$ ise T-H eğrisidir. Buradaki $\mathrm{H}$ ifadesi ise, $\mathrm{T}-\mathrm{N}$ eğrisi verilen malzemenin her bir tork değerinde 1 tur dönüş sonucunda ne kadar hasar aldığını göstermekte ve Denklem 5'te görüldüğü gibi hesaplanmaktadır.

$H=\frac{1}{\mathrm{~N}}$

Şekil 11b'ye bakılacak olursa, $600 \mathrm{Nm}$ tork iletildiğinde, malzemenin her bir dönüş turunun, ömrünü $2.5 * 10^{-5}(\% 0.0025)$ oranda azalttığ sonucuna varılmaktadır.

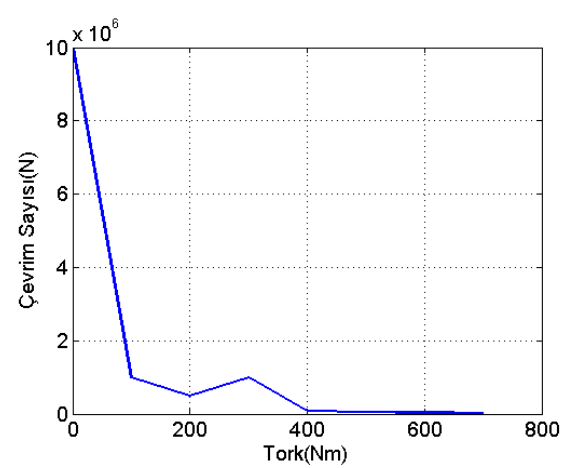

a) T-N Eğrisi (Lee ve Barkey, 2005)

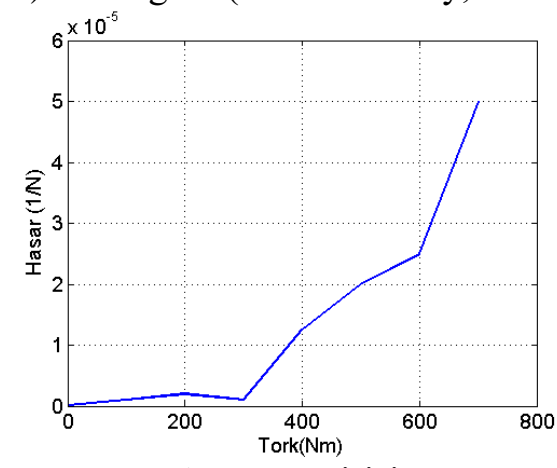

b) T-H Eğirisi

Şekil 11. Deneysel olarak elde edilen T-N ve T-H eğrileri
Mevcut metrobüslerin şaft malzemesine ait yorulma analizlerinin elde edilmesi başlı başına farklı bir çalışmanın konusudur. Bu nedenle bu çalışmada, daha önceden bu analizleri yapılmış malzemenin, mevcut aracın tork büyüklüklerine göre ölçeklendirilmiş değerleri kullanılmaktadır. $\mathrm{Bu}$ ölçeklendirilmiş T-H eğrisi Şekil 12'de gösterilmiştir. Bölüm 5'te anlatılan güç yönetim kontrolörü çalışması, gerçek hesaplanacak T-H eğrisi için de uygulanabilecek bir yapıdadır.

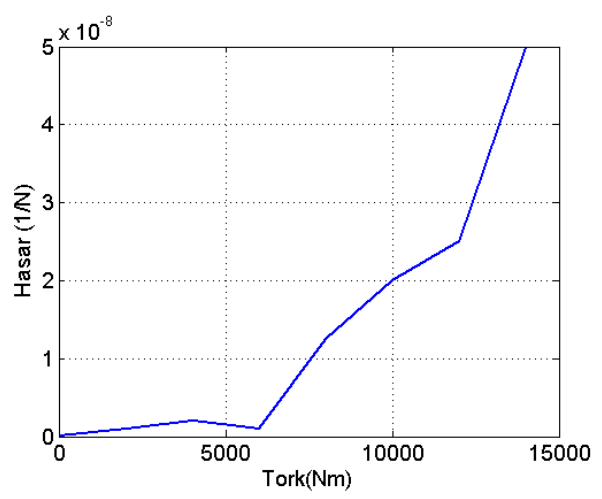

Şekil 12. Ölçeklendirilmiş T-H eğrisi

\section{4. Önerilen Hibrit Mimari}

Şekil 11'de gösterilen S-N, T-N ve T-H eğrilerindeki doğrusal olmayan ilişki, tüm malzemeler için geçerli olmakla birlikte (Rice, 1997), bu lineer olmayan ilişki, araç tork aktarım karakteristiğinde yapılacak ufak değişikliklerde önemli ömür artımlarıyla sonuçlanabileceğini göstermektedir. Örneğin Şekil 11 ve Şekil 12 incelenecek olursa, şaftın aldığı hasar miktarı, torkun belirli değerlerinden sonra oldukça yüksek oranlarda artmaktadır. Bu nedenle bu çalışmada, metrobüslerde şaft ömrünün artırılması amacıyla, Şekil 13'te gösterilen ve kolaylikla elde edilebilecek hibrit mimari önerilmiştir. Farklı hibrit mimariler hakkında ayrıntılı bilgiler Emadi vd. (2005)'de yer almaktadır.
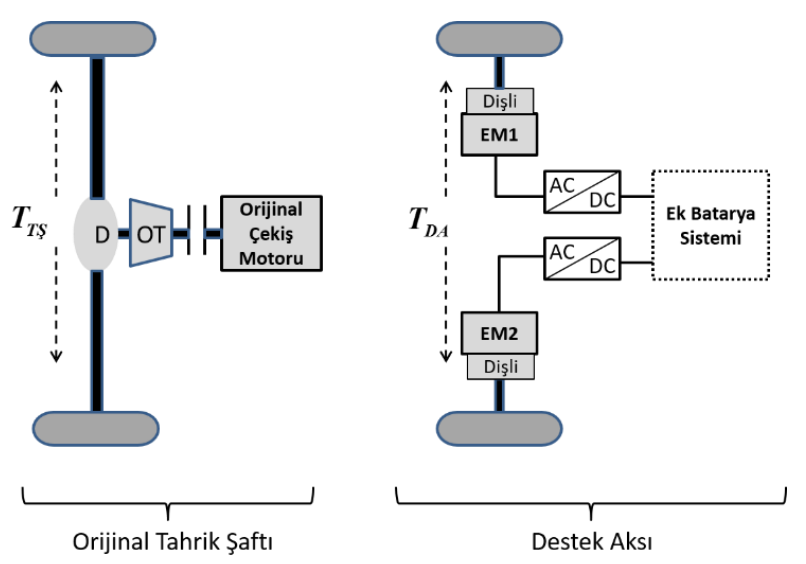

Şekil 13. Önerilen hibrit mimarisi (D: diferansiyel, OT: otomatik transmisyon) 
Şekil 13 incelenecek olursa, önerilen mimaride, orijinal çekiş motoruyla elektrik motorları arasında doğrudan bir bağlantı bulunmamaktadır. Elde edilen paralel hibrit mimarisinde şarj işlemi, orijinal çekiş motorunun üreteceği torkun yol aracılığıla destek aksına iletilmesiyle veya geri kazanımlı frenleme ile gerçekleşmektedir. Araç ilk durumda orijinal tahrik şaftı üzerinden orijinal çekiş motoru yardımıyla tek bir şaft üzerinden sürüşünü sağlamaktaydı. Önerilen yeni mimaride ise, orijinal çekiş motorundan görece daha ufak elektrik motorları sabit bir dişli oranıyla doğrudan tekerleklere bağlanmıştır. Şekil 7'de gösterilen elektrik motoru tork-hız eğrisi ve aracın çıktı̆̆ hızlar göz önüne alındığında, elektrik motorunun aracın tüm hızlarında tork üretebilmesi için dişli oran1 10 olarak belirlenmiştir. Araçta daha önce kullanılmayan akslardan biri bu amaçla kullanılmış ve buna da destek aksı adı verilmiştir. Doğrudan tekerlere bağlanan 2 elektrik motoru sayesinde, tek bir merkezden tahrik edildiğinde kullanılmas1 gereken diferansiyel sisteminin mekanik verim kayıplarından da kurtulmuş olunacaktır. EM1 ve EM2 olarak eklenen 2 elektrik motoruna elektriksel güç sağlayacak ek batarya sistemi ise, kontrolörün karar vereceği durumlarda EM1 ve EM2'nin jeneratör olarak çalıştırılmasıyla yol üzerinden şarj edilecektir. Önerilen bu mimari sayesinde, EM1 ve EM2'nin yüksek tork taleplerinde destek aksından yapacağ 1 ufak katkılarla, orijinal şaftta yüksek ömür artışları sağlanması hedeflenmiştir.

\section{Güç Yönetim Kontrolörü Tasarımı}

Şekil 10 'da gösterilen grafiğe göre, örnek çevrim esnasında orijinal aracın ürettiği tork kalkış anında $8000 \mathrm{Nm}$ değerlerine kadar çıkmaktadır. Metrobüs güzergahının yüksek eğimli bölgelerinde bu tork değerleri uzun süreler boyunca yüksek değerlerde seyredebilmektedir. $\mathrm{Bu}$ da önceki bölümlerde bahsedildiği üzere yüksek miktarda yorulmaya ve sonucunda mekanik problemlere neden olmaktadır. Bu çalışmada kullanılan ve Şekil 12 'de görülmekte olan tork-hasar eğrisi incelendiğinde, $6000 \mathrm{Nm}$ 'den itibaren hasar miktarının oldukça fazla arttığı görülmektedir.

Klasik hibrit araçlarda, yakıt tüketimi veya emisyonları azaltmaya yönelik kontrol metodları üzerinde oldukça fazla sayıda çalışma yapılmıştır. Bunlar arasında; kural tabanlı yaklaşımlar (Baumann vd., 2000; Kessels vd., 2008), dinamik programlama (Prez vd, 2006) (Vagg vd., 2016), model öngörülü kontrol (Ripaccioli vd., 2009), öğrenme tabalı kontrol (Liu vd., 2017) ve eşdeğer maliyet tüketimi minimizasyonu (Sezer ve
Gökaşan, 2012; Paganelli vd., 2000) sıralanabilir. $\mathrm{Bu}$ çalışmada ise güç yönetim kontrolörünün amacı önceki çalışmalardan daha farklıdır. Güç yönetim algoritmas1, uygun zamanlarda harici elektrik motorlarını devreye sokarak tork isteğinin yüksek seyrettiği kısımlarda yükün bir kısmını üzerine alarak aracın orijinal tahrik sistemi tarafindan üretilmesi gereken torku azaltmak amacıyla geliştirilmiştir. Mevcut kontrolör, tork isteği düşük seviyelerde seyrederken, normal durum içerisinde yer alır ve ihtiyaç duyulan tork miktarının tamamını orijinal çekiş motoru üzerinden sağlar. Tork isteği belirli bir değerin üzerine çıktığında, batarya şarj durumu (SOC) da elverişliyse destek durumuna geçerek harici motorları devreye sokmakta ve metrobüsün kendi tahrik sisteminin üretmesi gereken tork miktarını azaltmaktadır. SOC miktarının azalması durumunda ise, ihtiyaç duyulan torktan daha fazlası araç tarafindan üretilerek şarj durumuna geçilir ve harici elektrik motorlarının jeneratör olarak çalışması sağlanmakta ve piller şarj edilmektedir. Tarif edilen kural tabanlı yaklaşıma ait sonlu durum makinesi gösterimi Şekil 14'te verilmiştir.

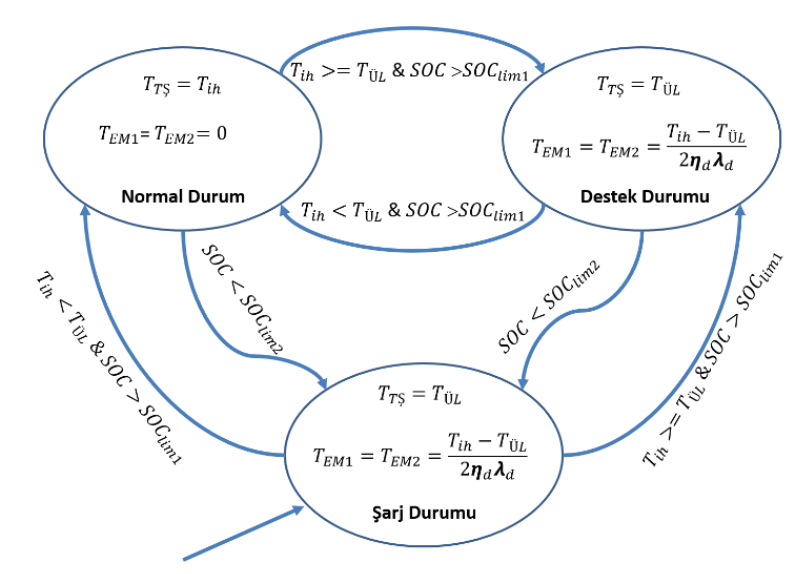

Şekil 14. Güç yönetim kontrolü - sonlu durum makinesi gösterimi

Şekil 14'e bakılacak olursa normal durum, sürücü tarafindan belirlenen ihtiyaç torkunun $\left(T_{i h}\right)$, belirlenen üst limitin $\left(T_{\ddot{U} L}\right)$, altında kaldığ 1 durumlarda geçerlidir. $\mathrm{Bu}$ üst limit, torkun yorulmayı (hasarı) göreli olarak daha az etkilediği bölgeye göre seçilir. Bu çalışmada kullanılan torkhasar eğrisine göre (Şekil 12), 6000Nm değeri $T_{\ddot{U} L}$ için uygun bir değer olarak görünmektedir. Normal durumda, $T_{\ddot{U} L}$ 'den düşük tork isteklerinde ihtiyaç duyulan torkun tamamı, orijinal çekiş motoru üzerinden tahrik şaftı $\left(T_{T S ̧}\right)$ aracılığıla verilir.

Destek durumuna geçiş ise, $T_{i h}$ 'in $T_{\ddot{U} L}$ 'nin üzerine çıkmasına ve batarya SOC değerine 
bağlıdır. Eğer SOC değeri belirlenen limitin $S O C_{\lim 1}$ üzerindeyse (batarya yeteri kadar doluysa) ve ihtiyaç duyulan tork üst limitin üzerindeyse destek durumu aktif hale gelir. Seçtiğimiz üst limit değerine göre, 6000Nm'nin üzerinde gelen tork taleplerinin $6000 \mathrm{Nm}$ 'lik k1sm1 orijinal tahrik şaftı üzerinden sağlanmakta, geri kalan k1sım ise elektrik motorları (EM1 ve EM2) tarafindan paylaşılmaktadır. Tekerleklere iletilen toplam torkun, ihtiyaç duyulan tork değerine eşit olması esastır. Bunun sağlanabilmesi için gerekli elektrik motor tork değerleri $\left(T_{E M 1}, T_{E M 2}\right)$, elektrik motorları önünde bulunan dişli oranı $(\mu)$ ve dişli mekanik verim $\left(\eta_{d}\right)$ değerleri de göz önüne alınarak aşağıdaki gibi hesaplanabilir.

$T_{E M 1}=T_{E M 2}=\frac{T_{i h}-T_{\ddot{U} L}}{2 \eta_{d}^{\mu}}$

Destek durumundan normal duruma geçiş şart1, ihtiyaç duyulan tork değerinin düşük değerlere gelmesidir. Destek durumundan geçiş yapılan diğer bir durum ise şarj durumudur.

Destek durumunda bir süre kalan aracın SOC değeri zamanla azalmak zorundadır. Bununla alakalı olarak şarj durumu, batarya SOC seviyesi önceden belirlenen ikinci bir limit değerinden $S O C_{\text {lim } 2}$ daha düşük olduğunda aktif hale gelmektedir. $S O C_{\lim 2}$ değeri, yukarıda bahsedilen $S O C_{\text {lim } 1}$ değerinden daha düşük seçilmelidir. $T_{E M 1}$ ve $T_{E M 2}$ değerleri, toplam torkun ihtiyaç duyulan torka eşit olması esasına göre Denklem (6)'daki ile aynı biçimde hesaplanır. Destek durumu ile temel fark ise, durumdan çıkış şartıyla alakalıdır. Şarj durumundan çıkmanın tek yolu SOC değerinin $S O C_{l i m 1}$ 'den daha yüksek hale gelmesidir. Bunun sağlanması için şarj durumu esnasında orijinal tahrik şaftı, ihtiyaç duyulan torktan bağımsız olarak sürekli üst limitinde $\left(T_{\text {ÜL }}\right)$ çalıştırılır. $\mathrm{Bu}$ da ihtiyaç duyulan tork değerine göre bataryanın daha çok şarj edilme eğiliminde olacağı anlamına gelmektedir. SOC seviyesi $S O C_{\text {lim } 1}$ 'in üzerine çıktığı andan itibaren, ihtiyaç duyulan tork değerine göre, tekrar normal duruma veya destek durumuna geçiş yapılır. Ayrıca güvenlik amacıyla ilk girilen durum şarj durumudur. Buradaki çalışmada $S O C_{\lim 1}$ değeri 0.61 ve $S O C_{\text {lim } 2}$ değeri de 0.59 olarak seçilmiştir.

\section{Benzetim Sonuçları}

Aracın orijinal durumundaki şaft ömrü ile önerilen hibrit mimari ve geliştirilen kural tabanlı kontrol yöntemi arasındaki farkları ortaya koyabilmek için Matlab/Simulink ${ }^{\circledR}$ ortamında benzetimler gerçekleştirilmiştir. Bölüm 2'de geliştirilen araç modeli kullanılmış ve Şekil 8'deki hız profili arka arkaya eklenerek metrobüsün yol alması sağlanmıştır. Benzetimlerde kullanılan önemli parametreler Tablo 2'de gösterilmiştir.

Tablo 2. Simülasyon parametreleri

\begin{tabular}{ll}
\hline Parametre & Değer \\
\hline Kütle & $30000 \mathrm{~kg}$ \\
Aerodinamik Direnç K.( $\rho)$ & 0.7 \\
Yuvarlanma Direnç K.(f) & 0.010 \\
Ön Projeksiyon Alanı (A) & $5.22 \mathrm{~m}^{2}$ \\
$S O C_{\text {lim } 1}$ & 0.61 \\
$S O C_{\text {lim } 2}$ & 0.59 \\
$T_{\text {ÜL }}$ & $6000 \mathrm{Nm}$ \\
EM Dişli Oranı $(\mu)$ & 10 \\
Dişli Verimi $\left(\eta_{d}\right)$ & 0.9 \\
Batarya Enerji Kapasitesi & $25 \mathrm{kWh}$ \\
\hline
\end{tabular}

Şekil 9'da gösterilen hiz profilinin 6 kez arka arkaya koşturulmasıyla elde edilen benzetim sonuçları Şekil 15'te gösterilmektedir. Şekil 15'te, orijinal durum ve hibrit çalışma durumunda tahrik şaftı tork miktarı değişimi ile hibrit durumdaki EM destek miktarı ve SOC değişimi bir arada gösterilmektedir.

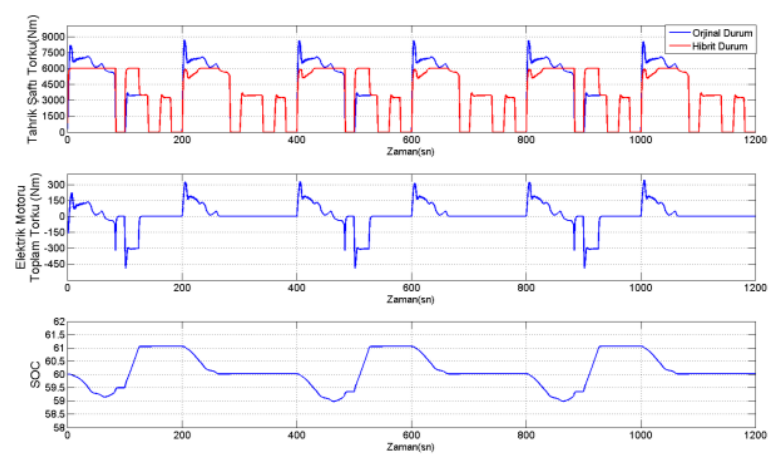

Şekil 15. Tahrik şaftı-EM tork değerleri ve SOC değişimi

Şekil 15 incelenecek olursa, algoritma istendiği gibi çalışmakta ve beklendiği gibi tahrik şaftını 6000Nm'nin üzerine hiç çıkarmamaktadır. Burada dikkat çeken noktalardan biri, ilk çalışma esnasında şarj durumunda başlanmasına rağmen, tork ihtiyacının ilk başlarda $6000 \mathrm{Nm}$ 'nin üzerinde seyretmesi nedeniyle SOC'un azalma eğiliminde olmasıdır. Fakat şarj seviyesi henüz 0.61 'e gelmediği için, tahrik şaftı $6000 \mathrm{Nm}$ tork üretmeye devam eder ve bir süre sonra bu değere ulaşılarak şarj durumundan çıkılır. Benzetimin sonraki süreçlerinde, SOC değeri beklenildiği gibi 0.590.61 arasında salınmaktadır. Elektrik motorlarının 
ne zaman destek olduğu ne zaman jeneratör olarak çalıştığı da yine Şekil 15'te gözlemlenebilmektedir. Grafiklere bakılacak olursa, orijinal durumda tahrik şaftının ürettiği tork değerleri $8000 \mathrm{Nm}$ civarına çıkabiliyorken, hibrit çalışma mimarisinde bu değer önceden belirlenen $6000 \mathrm{Nm}$ ile sınırlanmıştır.

Son olarak, orijinal çalışma durumu ile geliştirilen hibrit çalışma durumlarını, çalışmanın ana amacı olan şaft ömürleri anlamında karşılaştırmak gerekmektedir. Önceki bölümlerde ifade edilen hasar tanımı, şaftın 1 tur döndüğünde ömrünün yüzde kaç azaldığını göstermekteydi ve Denklem 5'le gösterilmişti. Bu durumda sürüş boyunca oluşacak toplam hasar değeri de Denklem (7) ile ifade edilebilir ( $\omega$ : Şaft dönüş hızı-devir/sn)

$T H=\int_{0}^{T} H w d t$

Denklem (6) kullanılarak Şekil 12'de ifade edilen tork-hasar grafiği yardımıyla sürüş sonunda şaft ömrünün ne kadar azaldığı hesaplanmıştır. Orijinal ve hibrit durumlar için elde edilen bu toplam hasar grafikleri Şekil 16'da gösterilmiştir.

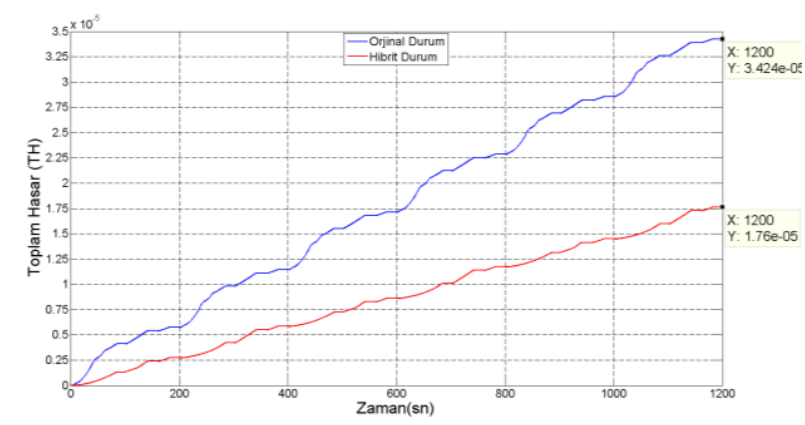

Şekil 16. Toplam hasar karşılaştırması

Şekil 16'daki veriler, 1200 saniyelik benzetim sonucunda, hız çevriminin $6 \mathrm{kez}$ arka arkaya koşturulmasıyla elde edilmiştir. Bu esnada kat edilen toplam mesafe de göz önünde bulundurularak, beklenen ömür değerleri hesaplanabilir. Toplam hasar değeri "1" olduğunda malzemenin ömrü bitmiş olacaktır. Buradan hareketle beklenen ömür (BÖ) değeri, kat edilen mesafenin (KM) toplam hasara $(\mathrm{TH})$ bölünmesiyle Denklem 8'deki gibi hesaplanmıştır.

$B \ddot{O}=\frac{\mathrm{KM}}{\mathrm{TH}}$

Tablo 3'te, orijinal durum ve önerilen hibrit mimari için karşılaştırmalı sonuçlar gösterilmektedir.
Tablo 3. Şaft ömrü karşılaştırması

\begin{tabular}{lcccc}
\hline $\begin{array}{c}\text { Kat edilen Mesafe } \\
\text { KM }(\mathrm{km})\end{array}$ & $\begin{array}{c}\text { Toplam Hasar } \\
(\mathrm{TH})\end{array}$ & $\begin{array}{c}\text { Beklenen } \\
\text { Ömür (BÖ) } \\
(\mathrm{km})\end{array}$ & $\begin{array}{c}\text { Ömür } \\
\text { Artış1 }\end{array}$ \\
\hline Orijinal & 11.539 & $3.424 * 10^{-5}$ & 373004 & - \\
Hibrit & 11.545 & $1.76 * 10^{-5}$ & 655966 & $\mathbf{\% 7 5 . 8 6}$ \\
\hline
\end{tabular}

Tablo 3 incelendiğinde, kat edilen mesafede çok ufak farklılıklar oluşmuştur. Bunun nedeni, hız kontrolörünün orijinal ve hibrit durumlardaki farklı mimariler nedeniyle performansinda meydana gelen ufak farklılıklardır. Tablo sonuçlarında görüldüğü üzere, önerilen hibrit mimari ve geliştirilen kontrol algoritması yardımıyla, şaftın beklenen ömrü 373004km'den, 655966km'ye çıkmaktadır. Bir başka deyişle beklenen ömürdeki artış \%75.86 olarak gerçekleşmiştir.

\section{Sonuçlar}

$\mathrm{Bu}$ yayında öncelikle, metrobüs taşıtlarının şaft ömürlerinin artırılması için veri toplama, modelleme ve harita elde etme çalışmaları gerçekleştirilmiştir. Bu çalışmalar neticesinde elde edilen benzetim ortamında, hibrit bir güç aktarım mimarisi önerisi yapılmış ve buna yönelik bir güç yönetim kontrolörü geliştirilmiştir. Modelleme hem orijinal metrobüs aracının dinamiği hem de çalıştıkları piste ait yol modeli olarak gerçekleşmiştir. Araçtan toplanan gerçek veriler yardımıyla, kontrol algoritmasının ihtiyaç duyduğu 2 giriş 1 çıkışlı pedal açıklığı-hız-tork haritası elde edilmiştir. Bunların yanında, algoritma testlerinde kullanabilmek amaciyla, istenen hız referansını izleyen bir hız kontrolörü de tasarlanarak modele dahil edilmiş ve bu sayede istenen hız profilinin, metrobüs hattının istenen bölümlerinde test edilebilmesi ve algoritma performans analizinin yapılabilmesi için model altyapısı tamamlanmıştır. Araç güç aktarım elemanlarının orijinal durumunda maruz kaldıkları yüksek tork değerlerinin azaltılmasına yönelik üst seviye güç yönetim algoritması geliştirilmiştir. Geliş̧irilen kural tabanlı bir kontrol yaklaşımı da yayın kapsamında sonuçlarıyla birlikte değerlendirilmiştir. Buna göre aracın orijinal şaft ömrünün, önerilen hibrit mimari ve geliştirilen kontrol yöntemiyle birlikte $\% 84.19$ oranda uzadığı, benzetim sonuçlarıyla gösterilmiştir.

Yayın içerisinde de belirtildiği üzere, kullanılan hasar-tork eğrisi, jenerik olarak seçilen bir eğrinin ölçeklenmiş halidir. İlgili referansta belirtilen yöntemle, mevcut metrobüslerin orijinal şaftına ait buna benzer bir eğri deneysel olarak ileriki 
çalışmalarda elde edilebilir. Bu durum, yayında verilen ömür uzama oranını doğrudan etkileyecektir. Bu çalışmada her ne kadar analizler şaft ekseninde yapılarak bir ömür artışı elde edilmiş olsa da, ana aks üzerindeki yükssek tork değerlerinin limitlendirilmesi, ana motordan tekerlere giden yol üzerindeki diğer tüm aktarma elemanlarının yorulmalarını da geciktirip ömürlerine olumlu katkı sağlayacaktır. İleriki çalışmalarda, her bir aktarma elemanı ayrı ayrı analiz edilerek verilen yaklaşımın bu komponentlerin ömürlerinde ne gibi etkileri olacağı incelenebilir.

Bugüne kadar hibrit araçlardaki güç dağıtım algoritmaları yakıt tüketimi ve emisyonların azaltılmasına yönelik tasarlanmıştır. Hibrit araç yaklaşımının mekanik aksamlardaki ömüre olan etkisini göz önüne almak, sıfırdan yapılacak hibrit araç tasarımlarında, mekanik aktarma organlarının boyutlandirmasina da olumlu katk1 sağlayabilecektir. Ayrıca sonraki aşamada, güç kontrol algoritmasının kural tabanlı bir yaklaşım yerine optimizasyon teknikleri kullanılarak geliştirilmesi de düşünülebilir.

\section{Kaynaklar}

Baumann BM, Washington G, Glenn BC, Rizzoni G. 2000, "Mechatronic Design and Control of Hybrid Electric Vehicles", IEEE/ASME Transactions on Mechatronics, 5(1), 58-72.

Bohn C, Atherton DP, 1995, "An Analysis Package Comparing PID Anti-Windup Strategies", IEEE Control Systems, 15(2), 34-40.

Brosilow C, Joseph B., 2002, Techniques of Model-Based Control, Prentice Hall Professional.

Emadi A, Rajashekara K., Williamson SS, Lukic SM., 2005, "Topological Overview of Hybrid Electric and Fuel Cell Vehicular Power System Architectures and Configurations" IEEE Transactions on Vehicular Technology, 54(3), 763-770.

Genta G., 1997, Motor Vehicle Dynamics Modeling and Simulation, Singapore, World Scientific.

Kessels J, Koot M, Bosch P, Kok D., 2008, "Online Energy Management for Hybrid Electric Vehicles" IEEE Transactions on Vehicular Technology, 57(6), 3428-3440.
Lee YL, Barkey ME., 2005, Development of Accelerated Life Test Criteria, Lee YL, Pan J, Hathaway R, Barkey M. Fatigue Testing and Analysis, Elsevier Inc., 313-337.

Liu T., Hu X., Li S., Cao D., "Reinforcement Learning Optimized Look-Ahead Energy Management of a Parallel Hybrid Electric Vehicle", 2017, IEEE/ASME Transactions on Mechatronics, 99, 1-11.

Paganelli G, Guerra T, Delprat S, Santin J, Delhom M, Combes E., 2000, "Simulation and Assessment of Power Control Strategies for a Parallel Hybrid Car," Proceedings of the Institution of Mechanical Part D: Journal of Automobile Engineering, 214(7), 705-717.

Pisu P, Rizzoni G., 2007, “A Comparative Study of Supervisory Control Strategies for Hybrid Electric Vehicles", IEEE Trans. Control Syst. Technol. 15(3), 506-518.

Pradhan MN, Gaikwad HT.,, 2015 "Fatigue Analysis of Composite Drive Shaft," International Journal of Engineering Research and Technology, vol. 4(5), 484489.

Prez RV, Bossio GR, Moitre D, Garca GO., 2006., "Optimization of Power Management in an Hybrid Electric Vehicle Using Dynamic Programming”, Mathematics and Computers in Simulation, 73(14), pp. $244-254$

Rajamani R., 2006. Vehicle System Dynamics and Control, United States, Springer.

Rice RC., 1997, SAE Fatigue Design Handbook, Society of Automotive Engineers.

Ripaccioli G, Bemporad A, Assadian F, Dextreit C, Cairano SD, Kolmanovsky IV., 2009, "Hybrid Modeling, Identification, and Predictive Control: An Application to Hybrid Electric Vehicle Energy Management", Proc. of Hybrid Systems: Computation and Control, 5469, 321-335.

Sezer V., Gökaşan M., Bogosyan S., 2011, “A Novel ECMS and Combined Cost Map Approach”, IEEE Trans. On Vehicular Technology, 60(8), 3557-3570.

Sezer V., Ünsal A.H., Timuçin B., Kurar A.F., Akçil L., 2015, Gökaşan M., Muğan A., "Metrobüs Çekiş Karakteristiğinin 
İyileştirilmesine Yönelik Veri ToplamaModelleme Çalışmaları ve Güç Dağıtım Kontrolörü Geliştirilmesi”, Otomatik Kontrol ulusal Konferans1, TOK 2015, Denizli, Türkiye, 729-734.

Shigley JE, Mischke CR, Budynas RG, Liu X, Gao Z., 1989, Mechanical Engineering Design, New York, USA, McGraw-Hill.
Siuru B., 2004, "Phileas: A New Idea in Public Transport", Mass Transit, 25(2), 44-46.

Vagg, C., Akehurst, S., Brace, C. J., Ash, L., 2016, "Stochastic Dynamic Programming in the Real-World Control of Hybrid Electric Vehicles". IEEE Transactions on Control Systems Technology, 24(3), 853866. 